\title{
Formação, crescimento e transições sólido-líquido e líquido-sólido de nanopartículas embebidas em vidros
}

\author{
Guinther Kellermann \\ Departamento de Física, Universidade Federal do Paraná
}

\begin{abstract}
O interesse em materiais compósitos nanoestrurados tem crescido significativamente nas últimas décadas devido às propriedades singulares das nanopartículas, que tornam esses materiais potenciais candidatos para aplicações na nanotecnologia. Muitas vezes essas propriedades são função da estrutura cristalina e tamanha dessas partículas. Por esse motivo, passa a ser importante a caracterização estrutural desses sistemas, determinando os processos de preparação que levem à formação de compósitos com as propriedades desejadas. Dentre as diversas técnicas que vêm sendo utilizadas na caracterização estrutural de nanopartículas está o espalhamento de raios X a baixo ângulo. Numerosos resultados mostram que está técnica é útil na obtenção de informações tais como: forma, tamanho médio e distribuição em tamanho de nanopartículas embebidas em matrizes. Particularmente interessantes são os estudos por SAXS realizados in situ, que, em muitos casos, permitem determinar os mecanismos envolvidos no crescimento das nanopartículas. Além disso, devido ao fato de que muitas propriedades das nanopartículas são função da sua estrutura cristalina (se estão na fase cristalina ou amorfa, por exemplo), torna-se importante também conhecer a dependência da temperatura de fusão e de cristalização com o tamanho dos nanocristais. Estudos mostram que em alguns casos as temperaturas de fusão dessas partículas podem ser centenas de graus $\mathrm{K}$ menores do que as temperaturas de fusão e cristalização, respectivamente, dos mesmos materiais com dimensões macroscópicas. Nesta apresentação serão mostrados resultados de estudos por SAXS da formação, crescimento e transições sólido-líquido e líquido-sólido de nanopartículas em vidros.
\end{abstract}

